\title{
Genotype and Haplotype of Interleukin-17F (IL-17F) in Peptic Ulcer in Iraqi Patients
}

\author{
ZainabAkbal $^{1}$, Abdalnabi J Abid ${ }^{2}$, Ekhlas Al-Shareefi ${ }^{3}$ \\ ${ }^{1}$ M.Sc., Student, Department of Biology, College of Science for Women, University of Babylon, ${ }^{2}$ Prof. Dr., \\ Department of Biology, College of Science for Women, University of Babylon, ${ }^{3}$ Assistant Prof. Dr., Department of \\ Biology, College of Science for women, University of Babylon
}

\begin{abstract}
A peptic ulcer can be described as a condition in which there is a discontinuity in the entire thickness of the gastric mucosa. The discontinuity can also involve the submucosa, and in some cases, the deeper layers of the muscle wall(1). Immunological serological and molecular factors play a great role in the susceptibility and diagnosis of this disease. IL-17F genotyping were reported to have an influencing in all types of peptic ulcer. The current study aims to detect some cytokine concentration (proinflammatory and Regulatory) in patients' blood, and some cytokine polymorphism. During the time from July 2019 to November 2019, the case-control study enrolled 318 blood samples collected from the patients who attended the Marjan Teaching Hospital- Hilla, as well as 60 healthy people. IL-17F genotyping was performing for 55 patients with peptic ulcer, and 30 healthy people as control, by using the PCR-SSP method. All types of peptic ulcers were significantly associated with IL-17F. Associations were also observed with IL-12A and IL-CXCR2. In conclusion, IL-17F, haplotypes, and genotypes have related to peptic ulcers so it can be dependent as a genetic marker for the susceptibility of this disease in Iraq.
\end{abstract}

Keywords: Gastric ulcer, Doudenal ulcer, Oesophagus ulcer, genotype, haplotype, IL17 F.

\section{Introduction}

A peptic ulcer is a lesion that may develop in gastric mucosa and submucosa or duodenum. Peptic ulcers develop because of increased acid secretion due to alcohol use, nonsteroidal anti-inflammatory drugs such as sedatives and aspirin, continuous and prolonged hunger, continuous stress, infection with Helicobacter pylori, and poor diet. Anticholinergic drugs, antihistamine, prostaglandin-like drugs and antimicrobials, proton pump inhibitors, and antimicrobial and anti-H. pylori antibiotics are the most important treatment lines for a peptic ulcer ${ }^{(2)}$. Most ulcers are caused by an infection with a type of bacteria called Helicobacter pylori (H. pylori). Patients with (PUD) caused by $H$. pylori infection were mostly in the middle age of $<50$ years (3). Infection with this microorganism plays a major role in the pathogenesis of gastric adenocarcinoma (GA) ${ }^{(4)}$.

An ulcer in the stomach is known as a gastric ulcer while that in the first part of the intestines is known as a duodenal ulcer. The incidence varies with age, gender, geographical location, and is associated with severe complications including hemorrhages, perforations, gastrointestinal obstruction, and malignancy. Thus, this clinical condition represents a worldwide health problem because of its high morbidity, mortality, and economic loss ${ }^{(5,6,7)}$. Gastric ulcer is one of the most common and serious chronic diseases of the upper gastrointestinal tract. The prevalence of gastric ulcers is $2.4 \%$ in the western population and maybe up to $6.1 \%$ in Asia ${ }^{(8)}$.

Gastric ulcer (GU) disease results from an interplay of environmental, microbial (Helicobacter pylori), pharmacological (non-steroidal anti-inflammatory drugs), excessive gastrin production (Zollinger-Ellison syndrome) and genetic factors (9). However, other causes like stress, smoking, spicy food, and nutritional deficiencies, can result in GU ${ }^{(10)}$. Diabetes is an independent risk factor for gastric ulcer bleeding (11). Duodenal Ulcer Occurs most often in the first portion of the duodenum) 12 (with $\sim 90 \%$ located within $3 \mathrm{~cm}$ of the pylorus. Ulcers can be demarcated, with depth at times reaching the muscularispropria. The base of the 
ulcer often consists of a zone of eosinophilic necrosis with surrounding fibrosis. Malignant duodenal ulcers (MDUs) are extremely rare and are more common than GUs in western countries ${ }^{(8)}$. An esophageal ulcer is a distinct break in the margin of the esophageal mucosa. This mucosal damage to the esophagus is often caused by gastroesophageal reflux disease or from severe sustained esophagitis from other causes $(13,14,15)$.

\section{Material and Method}

Patients and Controls: Three hundred Eighteen blood samples were collected from clinically diagnosed peptic ulcer patients who regularly admitted by medical committee specialized medicals center of the digestive system of Marjan hospital (Babylon) from July 2019 to November 2019, the age of patients between $(\leq 10-80)$ years including both sex male (156) and female (162), in addition to (60) samples were taken from apparently healthy human was taken from Babylon province as control. The study was approved by the Research Ethics Review Boards of the University of Babylon. Patients with peptic ulcers, including the newly and long-time diagnosed patients, were diagnosed according to the specialized physician, some of them were suffering from chronic diseases and others have a history with medication, in addition to other causes such as smoking, H.pylori, stress..etc.

Blood Sampling: The venous blood was collected from the patients and healthy persons by using $(5 \mathrm{ml})$ syringes, and then separated to $(2 \mathrm{ml})$ with anticoagulant tube and $(3 \mathrm{ml})$ without anticoagulant, The blood samples without anticoagulant allowed clotting at room temperature and then serum was separated by centrifugation at $(3000 \mathrm{rpm})$ for $(5 \mathrm{~min})$, and that was within 2-3 hours after collection (16). Blood samples with anticoagulants were used for the DNA extraction by using a specific DNA extraction kit, which performed according to the protocols recommended by the manufacturer (Favorgen/Taiwan).

IL 17 F genotype analysis: IL $17 \mathrm{~F}$ genotype was performed with PCR-sequence-specific primers (PCRSSP). The total volume of PCR Eppendorf tube for 17 F was prepared of $25 \mu 1$, by adding $2.5 \mu \mathrm{DNA}$ and $1 \mu 1$ from each reverse and forward 1, 2 of the primer to PCR Eppendorf tube containing $12.5 \mu 1$ master mix then $8 \mu 1$ nuclease-free water was added for reach the final volume $(25 \mu 1)$. The DNA amplification for IL17 F includes an initial denaturation of $5 \mathrm{~min}$ in $94^{\circ} \mathrm{C}, 32$ cycles of amplification (every cycle consists of denaturation of 30 $\mathrm{s}$ in $95^{\circ} \mathrm{C}$, hybridization of primers during $30 \mathrm{~s}$ in $58^{\circ} \mathrm{C}$, and an extension of $30 \mathrm{~s}$ in $72^{\circ} \mathrm{C}$ ), and a final extension of $10 \mathrm{~min}$ in $72^{\circ} \mathrm{C}$, then the PCR products were separated in $1.5 \%$ agarose electrophoresis system using ethidium bromide then visualized with the gel documentation, with 100 bp-ladder (Bioneer, Korea) and photographed. The sequences of primers used for the amplification of the genes are presented in table 1 .

Table 1: Sequences of the couples of primers used for the amplification of the genes.

\begin{tabular}{|l|c|c|c|}
\hline Reference & Size (bp) & Sequence 5-3 & Gene name \\
\hline & & 5'-GGATATGCACCTCTTACTGCACTT-3' & Primer 17 F \\
Rolandelli et al., 2019 & \multirow{2}{*}{$106 \mathrm{bp}$} & 5'-GGATATGCACCTCTTACTGCACTC-3' & rs (763780) \\
& & 5'-CACCAAGGCTGCTCTGTTTCTT -3' & \\
\hline
\end{tabular}

Statistical Analysis: All data were statistically analyzed according to software program SPSS version 20 statistical software (SPSS version 20, Inc., Chicago, IL, USA). The identified Primer $17 \mathrm{~F}$ and association between type of peptic ulcer, alleles, haplotypes, and genotypes were assessed using the odds ratio with its 95\% confidence interval (OR, CI 95 percentage).

\section{Results}

The present study reveals a noticeable variety of IL17F haplotype among the type of peptic ulcers. IL17F discriminated by PCR assay.

\section{The distribution of interleukin-17F genotyping} between patients and control: The distribution of interleukin-17F (IL-17F T $>$ C) genotyping (55 patients and 30 control) the result of patients showed (36 of which showed T/C genotype, 13 showed T/T genotype and 6 samples showed $\mathrm{C} / \mathrm{C}$ genotype) while the control group showed (16 of which showed T/C genotype, 9 showed $\mathrm{C} / \mathrm{C}$ genotype and 5 samples showed $\mathrm{T} / \mathrm{T}$ genotype), Table (2). 
Table (2): The distribution of interleukin-17F genotyping between patients and control

\begin{tabular}{|c|c|c|c|c|c|c|}
\hline \multicolumn{2}{|c|}{ Patients } & \multicolumn{2}{c|}{ Control } & \multirow{2}{*}{ OR } & \multirow{2}{*}{ Chi-Square (P.Value) } \\
\cline { 1 - 4 } Genotype & Sample No. & Genotype & Sample No. & & & 0.030 \\
\hline $\mathrm{C} / \mathrm{C}$ & 6 & $\mathrm{C} / \mathrm{C}$ & 9 & 0.285 & $0.090-0.905$ & 0.194 \\
\hline $\mathrm{T} / \mathrm{C}$ & 36 & $\mathrm{~T} / \mathrm{C}$ & 16 & 1.658 & $0.669-4.108$ & 0.323 \\
\hline $\mathrm{T} / \mathrm{T}$ & 13 & $\mathrm{~T} / \mathrm{T}$ & 5 & 1.548 & $0.493-4.859$ & \\
\hline Total & $\mathbf{5 5}$ & & $\mathbf{3 0}$ & \multicolumn{3}{l}{} \\
\hline
\end{tabular}

The distribution of interleukin-17F according to the site of the ulcer: The distribution of interleukin-17F (IL-17F T $>$ C) genotyping according to site ulcer show that high appearance in all types, for Gastric Ulcer, TT genotypes high appearance $9(32.14 \%)$ with high OR(4.926)(p. value 0.004) (CI 1.619-14.992) while CC show only $3(10.71 \%)$ with OR(1.282)(p. value 0.54$)(\mathrm{CI}$ 0.260-6.315), for Doudenal Ulcer, TT genotypes show $2(13.33 \%)$ with high OR(5.167))(p. value 0.0001) (CI
2.824-8.464) while CC show 2(13.33\%) with OR(1) (p. value 0.665) (CI 0.161-6.192), for Oesophagus Ulcer, TT genotypes show 2(16.66\%) with high OR(11.66) (p. value 0.002) (CI 2.116-64.326) while CC show 1(8.33\%) with OR(1.692)(p. value 0.554) (CI 0.16916.912), so TT genotypes had a Risk factor in the type of Peptic Ulcer while CC genotypes had a protective effect in a type of Peptic Ulcer, Table (3).

Table 3: Distribution of patient samples of interleukin-17F (IL-17F) according to the site of the ulcer with genotype.

\begin{tabular}{|l|c|c|c|c|c|c|}
\hline Object & Sample No. & Genotype & Sample No. & OR & CI & Chi-Square (P.Value) \\
\hline \multirow{3}{*}{ Gastric Ulcer } & \multirow{3}{*}{28} & $\mathrm{C} / \mathrm{C}$ & $3(10.71 \%)$ & 1.282 & $(0.260-6.315)$ & 0.540 \\
\cline { 3 - 7 } & & $\mathrm{T} / \mathrm{C}$ & $16(57.14 \%)$ & 0.150 & $(0.044-0.507)$ & $0.001^{* *}$ \\
\cline { 3 - 7 } & \multirow{3}{*}{ Doudenal Ulcer } & $\mathrm{T} / \mathrm{T}$ & $9(32.14 \%)$ & 4.926 & $(1.619-14.992)$ & $0.004^{* *}$ \\
\hline \multirow{3}{*}{ Oesophagus Ulcer } & \multirow{2}{*}{15} & $\mathrm{C} / \mathrm{C}$ & $2(13.33 \%)$ & 1.000 & $(0.161-6.192)$ & 0.665 \\
\cline { 3 - 7 } & & $\mathrm{T} / \mathrm{C}$ & $11(73.33 \%)$ & 0.073 & $(0.016-0.324)$ & $0.0001^{* *}$ \\
\cline { 3 - 7 } & \multirow{3}{*}{12} & $\mathrm{~T} / \mathrm{T}$ & $2(13.33 \%)$ & 5.167 & $(2.824-8.464)$ & $0.0001^{* *}$ \\
\hline & & $\mathrm{C} / \mathrm{C}$ & $1(8.33 \%)$ & 1.692 & $(0.169-16.912)$ & 0.554 \\
\cline { 3 - 7 } & & $\mathrm{T} / \mathrm{C}$ & $9(75 \%)$ & 0.067 & $(0.013-0.337)$ & $0.001^{* *}$ \\
\cline { 3 - 7 } & & $\mathrm{T} / \mathrm{T}$ & $2(16.66 \%)$ & 11.667 & $(2.116-64.326)$ & $0.002^{* *}$ \\
\hline
\end{tabular}

The distribution of interleukin-17F according to the cause of the ulcer: The distribution of interleukin17F (IL-17F T $>$ C) genotyping according to cause ulcer show that high appearance in all types, Bacterial Ulcer TT genotypes high appearance $10(33.33 \%)$ with high OR(4.667)(p. value 0.004) (CI 1.571-13.866) while CC show only $2(6.66 \%)$ with OR(2.154) (CI 0.363-12.764), Active bleeding Ulcer TT genotypes show 2(13.33\%) with high OR(5.167)(p .value 0.0001) (CI 2.824-8.464) while CC show $3(20 \%)$ with OR(0.615))(p. value 0.429$)$ (CI 0.119-3.191), Stress Ulcer TT genotypes show $1(10 \%)$ with high OR(12)(p. value 0.001$)$ (CI 2.30719.168) while CC show $1(10 \%)$ with OR(1.385) (p. value 0.633) (CI 13.6-14.071), so TT genotypes had a Risk factor in the type of Peptic Ulcer while CC genotypes had a protective effect in a type of Peptic Ulcer, table (4). 
Table (4): Distribution of patient samples of interleukin-17F (IL-17F) according to the cause of the ulcer with genotype.

\begin{tabular}{|c|c|c|c|c|c|c|}
\hline Object & Sample No. & Genotype & Sample No. & OR & CI & Chi-Square (P.Value) \\
\hline \multirow{3}{*}{ Becterial Ulcer } & \multirow{3}{*}{30} & $\mathrm{C} / \mathrm{C}$ & $2(6.66 \%)$ & 2.154 & $(0.363-12.764)$ & 0.335 \\
\hline & & $\mathrm{T} / \mathrm{C}$ & $18(60 \%)$ & 0.133 & $(0.040-0.446)$ & $0.001 * *$ \\
\hline & & $\mathrm{T} / \mathrm{T}$ & $10(33.33 \%)$ & 4.667 & $(1.571-13.866)$ & $0.004 * *$ \\
\hline \multirow{3}{*}{$\begin{array}{l}\text { Active bleeding } \\
\text { Ulcer }\end{array}$} & \multirow{3}{*}{15} & $\mathrm{C} / \mathrm{C}$ & $3(20 \%)$ & 0.615 & $(0.119-3.191)$ & 0.429 \\
\hline & & $\mathrm{T} / \mathrm{C}$ & $10(66.66 \%)$ & 0.100 & $(0.024-0.422)$ & $0.001 * *$ \\
\hline & & $\mathrm{T} / \mathrm{T}$ & $2(13.33 \%)$ & 5.167 & $(2.824-8.464)$ & $0.0001 * *$ \\
\hline \multirow{3}{*}{ Stress Ulcer } & \multirow{3}{*}{10} & $\mathrm{C} / \mathrm{C}$ & $1(10 \%)$ & 1.385 & $(13.6-14.071)$ & 0.633 \\
\hline & & $\mathrm{T} / \mathrm{C}$ & $8(80 \%)$ & 0.050 & $(0.008-0.309)$ & $0.001 * *$ \\
\hline & & $\mathrm{T} / \mathrm{T}$ & $1(10 \%)$ & 12.000 & $(2.307-19.168)$ & $0.001 * *$ \\
\hline
\end{tabular}

The distribution of interleukin-17F according to the gender of the ulcer: The distribution of the interleukin-17F (IL-17F $\mathrm{T}>\mathrm{C}$ ) genotyping according to the gender through the below table, notice that the genotype of the genes shows that the $(\mathrm{C} / \mathrm{T})$ gene in patient samples with percentage $65.45 \%$ was dominant, where the ratio was $36 \%$ divided by 21 females and 15 males, while the control was the same by 8 for each gender, while the $(\mathrm{T} / \mathrm{T})$ gene with percentage $23.63 \%$ ranked second in terms of genotype where $11 \%$ of the patients were divided into 8 females and 5 males, but the control was for females higher than males, while the third gene $(\mathrm{C} / \mathrm{C})$ constituted $10.9 \%$ of the total samples was the lowest in terms of genotype at $6 \%$ distributed for females by $4 \%$ males $2 \%$ However, it is noteworthy that the percentage of control was higher than the previous percentage of genes, as it was shown that this gene was higher in females than males, table (5).

Table (5): Distribution patient samples of interleukin-17F (IL-17F) genotype and control according to gender.

\begin{tabular}{|c|c|c|c|c|c|c|}
\hline Genotype & Gender & Patients & Control & OR & CI & Chi-Square (P.Value) \\
\hline \multirow{2}{*}{$\mathrm{C} / \mathrm{C}$} & Female & $4(66.66 \%)$ & $4(44.44 \%)$ & \multirow{2}{*}{2.500} & \multirow{2}{*}{$(0.292-21.399)$} & \multirow{2}{*}{0.378} \\
\hline & Male & $2(33.33 \%)$ & $5(55.55 \%)$ & & & \\
\hline \multirow{2}{*}{$\mathrm{C} / \mathrm{T}$} & Female & $21(58.33 \%)$ & $8(50 \%)$ & \multirow{2}{*}{1.400} & \multirow{2}{*}{$(0.429-4.570)$} & \multirow{2}{*}{0.577} \\
\hline & Male & $15(41.66 \%)$ & $8(50 \%)$ & & & \\
\hline \multirow{2}{*}{$\mathrm{T} / \mathrm{T}$} & Female & $8(61.53 \%)$ & $3(60 \%)$ & \multirow{2}{*}{1.067} & \multirow{2}{*}{$(0.129-8.793)$} & \multirow{2}{*}{0.676} \\
\hline & Male & $5(38.46 \%)$ & $2(40 \%)$ & & & \\
\hline
\end{tabular}

The distribution of interleukin-17F according to the age group of the ulcer: The distribution of interleukin-17F (IL-17F T $>$ C) genotyping according to age group, showed a significant moral difference in the following age groups (11-20) show genotype (T/T) high appearance with high OR(21)(p.value 0.001), (31-40)) show genotype (T/T) high appearance with high OR(7) (p.value 0.029), (41-50)) show genotype (T/T) high appearance with high OR(11.66)(p.value 0.024), (51-60) show genotype (T/T) high appearance with high OR(7) (p.value 0.029), so SNPs in samples show revealed high prevalence of $(\mathrm{C} / \mathrm{T})$ genotype in patient samples with 
percentage $65.45 \%$ and $(\mathrm{T} / \mathrm{T})$ genotype in the second place with percentage $23.63 \%$, while $(\mathrm{C} / \mathrm{C})$ constituted $10.9 \%$ of the total samples, As for his part OR we notice the overpowering $\mathrm{T} / \mathrm{T}$ where was his highest value in age (11-20) (21), Table (6).

Table (6): Distribution of patient samples of interleukin-17F (IL-17F) genotype according to age group.

\begin{tabular}{|c|c|c|c|c|c|c|}
\hline Age group (years) & Sample No. & Genotype & Sample No. & OR & CI & Chi-Square (P.Value) \\
\hline \multirow{3}{*}{$\geq 10$} & \multirow{3}{*}{3} & $\mathrm{C} / \mathrm{C}$ & 0 & - & - & 0 \\
\hline & & $\mathrm{C} / \mathrm{T}$ & 3 & - & - & $0.010^{*}$ \\
\hline & & $\mathrm{T} / \mathrm{T}$ & 0 & - & - & 0 \\
\hline \multirow{3}{*}{$11-20$} & \multirow{3}{*}{10} & $\mathrm{C} / \mathrm{C}$ & 1 & 0.135 & $(0.136-14.071)$ & 0.633 \\
\hline & & $\mathrm{C} / \mathrm{T}$ & 8 & 0.050 & $(0.008-0.309)$ & $0.001 * *$ \\
\hline & & $\mathrm{T} / \mathrm{T}$ & 1 & 21.000 & $(2.307-191.168)$ & $0.001 * *$ \\
\hline \multirow{3}{*}{$21-30$} & \multirow{3}{*}{14} & $\mathrm{C} / \mathrm{C}$ & 1 & 2.000 & $(0.202-19.754)$ & 0.485 \\
\hline & & $\mathrm{C} / \mathrm{T}$ & 6 & 0.267 & $(0.064-1.113)$ & 0.070 \\
\hline & & $\mathrm{T} / \mathrm{T}$ & 7 & 2.333 & $(0.632-8.619)$ & 0.171 \\
\hline \multirow{3}{*}{$31-40$} & \multirow{3}{*}{8} & $\mathrm{C} / \mathrm{C}$ & 1 & 1.077 & $(0.103-11.234)$ & 0.721 \\
\hline & & $\mathrm{C} / \mathrm{T}$ & 5 & 0.120 & $(0.021-0.673)$ & $0.009 * *$ \\
\hline & & $\mathrm{T} / \mathrm{T}$ & 2 & 7.000 & $(1.180-41.536)$ & $0.029 *$ \\
\hline \multirow{3}{*}{$41-50$} & \multirow{3}{*}{6} & $\mathrm{C} / \mathrm{C}$ & 1 & 0.769 & $(0.070-8.405)$ & 0.622 \\
\hline & & $\mathrm{C} / \mathrm{T}$ & 4 & 0.100 & $(0.014-0.703)$ & $0.024 *$ \\
\hline & & $\mathrm{T} / \mathrm{T}$ & 1 & 11.667 & $(1.188-114.590)$ & $0.024 *$ \\
\hline \multirow{3}{*}{$51-60$} & \multirow{3}{*}{8} & $\mathrm{C} / \mathrm{C}$ & 1 & 1.077 & $(0.103-11.234)$ & 0.721 \\
\hline & & $\mathrm{C} / \mathrm{T}$ & 5 & 0.120 & $(0.021-0.673)$ & $0.019^{*}$ \\
\hline & & $\mathrm{T} / \mathrm{T}$ & 2 & 7.0000 & $(1.180-41.536)$ & $0.029 *$ \\
\hline \multirow{3}{*}{$61-70$} & \multirow{3}{*}{5} & $\mathrm{C} / \mathrm{C}$ & 1 & 0.615 & $(0.054-6.947)$ & 0.561 \\
\hline & & $\mathrm{C} / \mathrm{T}$ & 4 & 0.050 & $(0.0050 .547)$ & $0.010^{*}$ \\
\hline & & $\mathrm{T} / \mathrm{T}$ & 0 & - & - & 0 \\
\hline \multirow{3}{*}{$71-80$} & \multirow{3}{*}{1} & $\mathrm{C} / \mathrm{C}$ & 0 & - & - & 0 \\
\hline & & $\mathrm{C} / \mathrm{T}$ & 1 & - & - & 0.194 \\
\hline & & $\mathrm{T} / \mathrm{T}$ & 0 & - & - & 0 \\
\hline Total & 55 & & 55 & & & \\
\hline
\end{tabular}




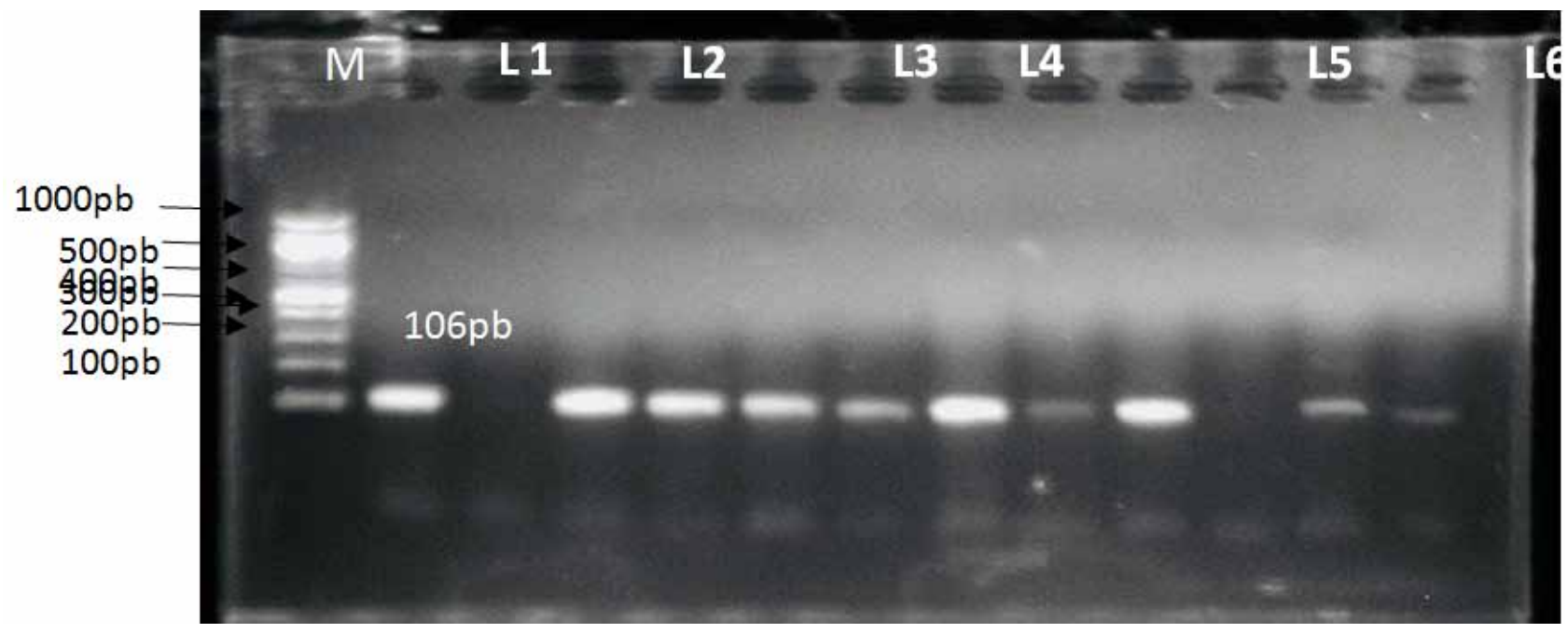

Figure (1):Agarose gel electrophoresis image for interleukin-17F gene (IL-17F) at $100 \mathrm{v}$ for $60 \mathrm{~min} . \mathrm{M}$, marker 100bp, $L$ 1, 2, 3,4,5,6 give positive results.

\section{Discussion}

The results showed a significant association of IL17F (IL-17F C>T) rs (763780) polymorphisms with susceptibility to the peptic ulcer (especially Gastric Ulcer GU), TT genotypes high appearance (23.63\%) while CC show (10.9\%), so TT genotypes had a Risk factor in the type of Peptic Ulcer while CC genotypes had a protective effect in a type of Peptic Ulcer.

These results agree with each of: ${ }^{(18)}$ by showing that TT appearance was at a high rate, ${ }^{(19)}$ by showing that TT genotypes were at a high appearance (38.8\%) while CC showed $(27.3 \%)$, ${ }^{(20)}$ by showing that TT genotypes were at a high appearance $(89.3 \%)$ while CC showed $(0.7 \%),{ }^{(21)}$ by showing that TT genotypes were at a high appearance $(97.0 \%)$ while CC showed (3\%), $(22,23,24,25,26)$, show that TT appearance was at a high rate.

While the study of ${ }^{(27)}$ showed CC genotypes high appearance $(81.59 \%)$ and TT show $(6.75 \%)$, (28) that showed CC genotypes high appearance $(94.91 \%)$ while TT show $(5.09 \%)$, excluded due to the relatively small sample size of our study. Previous studies have identified the IL-17 F polymorphism as a potential genetic marker for gastric cancer risk ${ }^{(29)}$.

In Bacterial Ulcer (H. pylori), TT genotypes show a high appearance (33.33\%) with high OR (4.667), while CC show only (6.66\%) with OR (2.154). Active bleeding Ulcer TT genotypes show (13.33\%) with high OR (15.167) while CC show (20\%) with OR (0.615)
(P. value 0.429) (CI 0.119-3.191), Stress Ulcer TT genotypes show (10\%) with high OR (21) while CC show (10\%) with OR (1.385).

Study of (27), for Bacterial Ulcer (H. pylori), TT genotypes were $(57.67 \%)$. For active bleeding Ulcer, TT genotypes show (44.48\%), while for stress Ulcer TT genotypes show $(34.36 \%)$. It was shown that this gene was higher in females $(60 \%)$ than males $(40 \%)$. ${ }^{(30,22,19,}$ ${ }^{20,26)}$ shown that higher in females than males. While ${ }^{(18)}$ show that was higher in males (41\%) than females (17\%), $(27,24)$ show that was higher in males than females due to a variety of environmental and host genetic factors.

The results showed a significant association of IL17F (IL-17F C $>$ T) rs (763780) polymorphisms with age groups (11-20) show genotype (T/T) high appearance with high $\mathrm{OR}{ }^{(12)}$ (P.value 0.001) and (31-40) show genotype $(\mathrm{T} / \mathrm{T})$ high appearance with high OR (7) (P.value 0.029). $(18,31)$ is associated with an increased risk for the severity of gastric mucosal atrophy in subjects younger than 60 years, ${ }^{(19)}$ shown that was higher in $\geq 50$ yr $(82.9 \%)$ than $<50 \mathrm{yr}(17.1 \%)$. While ${ }^{(27)}$ show that was higher in $<60(56.13 \%)$ than $\geq 60(43.87 \%)$ due to a variety of behavioral factor like smoking and a high salt diet.

\section{Conclusion}

This study was designed to assess the associations of IL 17F, haplotypes, and genotypes with the risk of developing a type of peptic ulcer in Iraq. Certain IL 17F, 
haplotypes, and genotypes were related to peptic ulcers and may be used as genetic susceptibility markers to peptic ulcers. Further studies of IL17F and peptic ulcer in Iraq are needed to confirm the present results and to provide data for the development of screening assays and for better management of patients with peptic ulcers at the onset of disease.

Financial Disclosure: There is no financial disclosure.

Conflict of Interest: None to declare.

Ethical Clearance: All experimental protocols were approved under the College of Science for women and all experiments were carried out in accordance with approved guidelines.

\section{References}

1. Kinnear M. Peptic Ulcer Disease. In: Walker, R. and Whittlesea, C. Clinical Pharmacy and Therapeutic. 5th Edition, Churchill Livingstone Elsevier. Edinburgh. 2012; 162- 184.

2. Zandi F, Shirzad H, Bagheri N, Ahmadi A, Azadegan F, Gharib A, et al. Evaluation of IL$17 \mathrm{~A}$ and IL-17F genes polymorphism in Iranian dyspeptic patients. Life Sci J. 2013; 10:544-51.

3. Eusebi LH, Zagari RM, Bazzoli F. Epidemiology of Helicobacter pylori infection. Helicobacter 2014; 19 Suppl 1:1-5.

4. Hussein N. Helicobacter pylori and gastric cancer in the Middle East: a new enigma? World journal of gastroenterology: WJG.2010; 16(26): 3226.

5. Brown L, Wilson, D. Gastroduodenal ulcers: causes, diagnosis, prevention and treatment. Comprehensive therapy,1999; 25(1): 30-38.

6. Dimaline, R, Varro, A. Attack and defence in the gastric epithelium-a delicate balance. Experimental physiology, 2007; 92(4): 591-601.

7. Najm W. Peptic ulcer disease. Primary Care: Clinics in Office Practice, 2011; 38(3): 383-394.

8. Sung J, Kuipers, E, El-Serag, H. Systematic review: the global incidence and prevalence of peptic ulcer disease. Alimentary pharmacology \& therapeutics, 2009; 29(9): 938-946.

9. Bashinskaya B, Nahed, B, Redjal, N. Trends in peptic ulcer disease and the identification of Helicobacter Pylori as a causative organism: population-based estimates from the US nationwide inpatient sample.
Journal of global infectious diseases, 2011; 3(4): 366.

10. Subrata R. Clinical Study of Peptic Ulcer Disease, Asian Journal of Biomedical and Pharmaceutical Sciences, 2016.

11. Peng, Y, Leu, H, Luo, J. Diabetes is an independent risk factor for peptic ulcer bleeding: A nationwide population-based cohort study. Journal of gastroenterology and hepatology, 2013; 28(8): 1295-1299.

12. Enaganti, S. Peptic ulcer disease. Hospital pharmacist, 2006; 3: 16-18.

13. Sung JJ, Kuipers EJ and El-Serag HB: Systematic review: The global incidence and prevalence of peptic ulcer disease. Aliment PharmacolTher. 2009; 29:938-946.

14. Scida S, Russo M, Miraglia C, Leandro G, Franzoni L, Meschi T, De' Angelis GL, Di Mario F. Relationship between Helicobacter pylori infection and GERD. Acta Biomed. 2018; 89(8-S):40-43.

15. Sasaki S, Nishikawa J, Goto A, Sakaida I. Dabigatran-induced Esophageal Ulcer at a Natural Constriction. Intern. Med. 2019; 58(5):757-758.

16. Spechler SJ. Proton Pump Inhibitors: What the Internist Needs to Know. Med. Clin. North Am. 2019; 103(1):1-14.

17. Lewis S, Bain, B, Bates, I. Practical haematology. Churchil Livingstone.2001.

18. Hayashi R, Tahara, T, Shiroeda, H. Association of genetic polymorphisms in IL17A and IL17F with gastro-duodenal diseases. J Gastrointestin Liver Dis, 2012; 21(3): 243-249.

19. Rafiei, A, Hosseini, V, Janbabai, G. Polymorphism in the interleukin-17A promoter contributes to gastric cancer. World Journal of Gastroenterology: WJG, 2013; 19(34): 5693.

20. Zacarias, J, Sippert E. The influence of interleukin $17 \mathrm{~A}$ and IL17F polymorphisms on chronic periodontitis disease in Brazilian patients. Mediators of inflammation, 2015.

21. Botros, S, Ibrahim, O, Gad, A. Study of the role of IL-17F gene polymorphism in the development of immune thrombocytopenia among the Egyptian children. Egyptian Journal of Medical Human Genetics, 2018; 19(4): 385-389.

22. Navratilova, Z, Gallo, J, Mrazek, F, Petrek, M. Genetic variation in key molecules of the Th-17 
immune response is not associated with risk for prosthetic joint infection in a Czech population. Biomedical Papers, 2012; 156(3): 248-252.

23. Bulat-Kardum, L, Etokebe, G, Lederer, P, Balen, $\mathrm{S}$, Dembic, Z. Genetic polymorphisms in the Tolllike receptor 10, Interleukin (IL) 17A and IL17F genes differently affect the risk for tuberculosis in Croatian population. Scandinavian journal of immunology, 2015; 82(1): 63-69.

24. Wang $\mathrm{M}, \mathrm{Xu}, \mathrm{G}, \mathrm{Lü}, \mathrm{L}, \mathrm{Xu}, \mathrm{K}$. Genetic polymorphisms of IL-17A, IL-17F, TLR4 and miR-146a in association with the risk of pulmonary tuberculosis. Scientific reports, 2016; 6(1): 1-12.

25. Choi B, Hong, J, Hong, J. The IL17F His161Arg polymorphism, a potential risk locus for psoriasis, increases serum levels of interleukin-17F in an Asian population. Scientific Reports, 2019; 9(1): 1-7.

26. Rolandelli A, Pellegrini J, Hernández Del Pino, R. The Non-Synonymous rs763780 SingleNucleotide Polymorphism in IL17F Gene Is Associated with Susceptibility to Tuberculosis and
Advanced Disease Severity in Argentina. Frontiers in immunology, 2019; 10: 2248.

27. Hou C, Yang, F. Interleukin-17A gene polymorphism is associated with susceptibility to gastric cancer. International Journal of Clinical and Experimental Pathology, 2015; 8(6): 7378.

28. PawlikA, Kotrych D, Malinowski D. IL17A and IL17F gene polymorphisms in patients with rheumatoid arthritis. BMC musculoskeletal disorders, 2016; 17(1): 208.

29. Tsugane S. Salt, salted food intake, and risk of gastric cancer: epidemiologic evidence. Cancer Sci. 2005; 96:1-6.

30. Paradowska-Gorycka A, Wojtecka-Lukasik E. Association between IL-17F gene polymorphisms and susceptibility to and severity of Rheumatoid Arthritis (RA). Scandinavian journal of immunology, 2010; 72(2): 134-141.

31. Bell, K, Del Mar, C, Wright, G. Prevalence of incidental prostate cancer: a systematic review of autopsy studies. International journal of cancer, 2015; 137(7): 1749-1757. 